\title{
Anesthetic Management in a Adult Male with Citrullinemia: A Case Report
}

\section{Gurdarshan Kamboj1, Mandeep Kaur ${ }^{2 *}$, Rakesh Sadhu ${ }^{3}$}

1PG $3^{\text {rd }}$ year, Department of Anesthesiology, Maharishi Markadeshwer medical College, Kumarhatti, Solan, Himachal Pradesh, India. Email: rsadhu2008@gmail.com,

Orcid ID: 0000-0002-0287-2203

2Professor. Department of Anesthesiology, Maharishi Markadeshwer medical College, Kumarhatti, Solan, Himachal Pradesh, India. Email: hkmg14@gmail.com,

Orcid ID: 0000-0002-8306-0150

${ }^{3} \mathrm{HOD} \&$ Professor, Department of Anesthesiology, Maharishi Markadeshwer medical college, Kumarhatti, Solan, Himachal Pradesh, India.

Email: drgurdarshankamboj@gmail.com

Orcid ID: 0000-0001-7514-2036

${ }^{*}$ Corresponding author

Received: 25 October 2021

Revised: 09 December 2021

Accepted: 23 December 2021

Published: 18 February 2022

\begin{abstract}
Our case report is regarding a patient who is a k/c/o citrullinemia type 1 which is a defect in urea cycle posted for facture patella reduction surgery (tension band wiring). He was intellectual disabled because of persistent hyperammonaemia before diagnosis that was controlled with benzoate and L- arginine. Patient preoperative fasting was kept to the minimum and taken as 1st case in the operation theatre. Drugs taken orally on routine basis were continued along with serum ammonia monitoring. Clonidine with midazolam along with propofol infusion to decrease protein hypercatabolism due to stress and to get co-operation of the patient for femoral sciatic block. Postoperative ammonia levels were normal. Sedation is considered useful for preventing hyper ammonemia. Preoperative endocrinology consultation, perioperative serum ammonia level monitoring and coordination between various health departments (nephrologist and endocrinologist) for appropriate care in case of hyper ammonemia and hyperglycaemia perioperatively.
\end{abstract}

Keywords:- Type I Citrullinemia, urea cycle, fracture patella, sciatico-femoral block.

\section{INTRODUCTION}

Citrullinemia type I (CTLN1) is a rare autosomal recessive genetic disorder. It has different forms like a classic acute neonatal form, a late-onset milder form, a form which may come during pregnancy or postpartum and an asymptomatic form. [1]

CTLN1 has incidence of approximately 1/57,000 births. [1]

CTLN1 results from the deficiency of the enzyme argininosuccinate synthetase (ASS). ASS is one out of six enzymes which play an important role in the removal of nitrogen from the body. This is done through urea cycle. The absence of this enzyme results in excessive accumulation of nitrogen, in the form of ammonia (hyperammonemia) in the blood and all body fluids.[2]

The symptoms of CTLN1 are results from the accumulation of ammonia in the blood and in the brain which is in cerebrospinal fluid (CSF). []

If untreated, CTLN1 may lead to coma which is mainly due to high levels of ammonia in the CSF (hyperammonemic coma). Neurological 
Annals of International Medical and Dental Research E-ISSN: 2395-2822 | P-ISSN: 2395-2814

Vol-8, Issue-2 | March-April 2022

DOI: 10.53339/aimdr.2022.8.2.1

Page no- 01-04 | Section- Research Article (Anesthesiology)

abnormalities which include developmental delay, intellectual disability and cerebral palsy may occur.[4]

Increased intracranial pressure can result in enhanced muscle tone, spasticity, abnormal reflex movements of the foot (ankle clonus), and seizures. If not treated, the disorder will result in life-threatening events.[5]

In some group of patients, in which there is partial deficiency of enzyme, onset of the disorder may not occur until later during infancy or childhood. Symptoms may include delayed milestone attainment, failure to grow and weight gain at the expected rate (failure to thrive), avoidance of high-protein foods from the diet, inability to coordinate voluntary movements (ataxia), progressive lethargy and vomiting. [6]

\section{CASE REPORT}

A 20 year-old boy, weighing $48 \mathrm{~kg}$, who was a known case of citrullinemia type 1, was admitted to our hospital for tension band wiring of patella. Patient had history of seizures from past 10 years. Patient suffered fracture of patella due to fall during active seizure. According to history given by parents of the patient, patient was diagnosed for citrullinema type 1, 10 years back when he had first episode of seizure which was refractory to medical line of management and required mechanical ventilation for 20 days. Since that time patient was taking Sodium benzoate per oral 2 g 6 hrly, L-arginine 250 mg 12hrly, Lcarnitine $500 \mathrm{mg}$ 8hrly, ranitidine $45 \mathrm{mg}$ 12 hrly, syrup of calcium, multivitamins plus zinc, and oxycarbamazepine, levetiracetam, clonazepam. On physical examination patient was found to be intellectually disabled, not oriented to time place and person. The American Society of Anesthesiologists (ASA) physical classification of the patient was ASA grade 2. Patient was given medicine as prescribed by physician on the day of surgey and also given tab pantoprazole $20 \mathrm{mg}$ on the day of surgery. Patient kept nill per oral from midnight and the operation was planned in the morning as first case. Plan of anaesthesia was ultrasound guided femoral and sciatic nerve block with sedation. Once patient had reached to operation theatre ECG, NIBP and pulse oximetry monitors were attached. A $18 \mathrm{G}$ intravenous line was secured and patient was given injection clonidine 60 microgram, injection midazolam $2 \mathrm{mg} i / \mathrm{v}$, inj glycopyrrolate 200 microgram i/v. Propofol infusion was started at rate of 50 microgram per $\mathrm{kg}$ per min. Oxygen was given with nasal prongs. Ringer lactate solution was infused during the operation. Once patient was sedated, patient was given ultrasound guided femoral and sciatic nerve block with $30 \mathrm{ml}$ of drug volume containing $15 \mathrm{ml}$ of $2 \%$ lignocaine and $15 \mathrm{ml}$ of $0.5 \%$ bupivacaine.

Blood glucose was tested every hour. The surgery was uneventful and lasted for 1 hour.

Postoperative patient was comfortable, painfree with no changes in hemodynamic variables. Postoperative investigations serum ammonia, arterial gas analysis was repeated after 24 hrs postoperatively which were normal and discharged after 5 days of uneventful stay in the hospital. 
Annals of International Medical and Dental Research E-ISSN: 2395-2822 | P-ISSN: 2395-2814

Vol-8, Issue-2 | March-April 2022

DOI: 10.53339/aimdr.2022.8.2.1

Page no- 01-04 | Section- Research Article (Anesthesiology)

Table 1: Perioperative Laboratory Test Results

\begin{tabular}{|c|c|c|}
\hline Variable & Preoperative & Postoperative \\
\hline Ammonium, $\mu \mathrm{mol} / \mathrm{dL}$ & 34 & 35 \\
\hline White cell count $10^{3} / \mathrm{uL}$ & 5.8 & \\
\hline Red cell count $10^{6} / \mathrm{uL}$ & 4.4 & \\
\hline Hemoglobin g/dL & 12,2 & \\
\hline Platelet count lacs $/ \mathrm{mm}^{3}$ & 1,90 & \\
\hline Hct \% & 32.5 & \\
\hline Arterial pH & 7.42 & 7.41 \\
\hline Arterial oxygen saturation (\%) & 98 & 99 \\
\hline Arterial tension of carbon dioxide (mmHg) & 29.8 & 30 \\
\hline Base excess, mEq/L & -5.2 & -5 \\
\hline $\mathrm{PaO} 2, \mathrm{mmHg}$ & 310 & 312 \\
\hline Urea, mg/dl & 20 & 22 \\
\hline Creatinine, mg/dl & 0.61 & 0.61 \\
\hline Total bilirubin & 0.9 & \\
\hline Direct bilirubin & 0.3 & \\
\hline SGOT/SGPT, u/1 & $55 / 80$ & \\
\hline Alkaline phosphatase & 204 & 211 \\
\hline Peripheral blood smear & Hypochromic and microcytic & \\
\hline Glucose, mg/dL & 108 & 111 \\
\hline Calcium, mg/dL & 8.9 & \\
\hline Sodium, mEq/L & 144 & 143 \\
\hline
\end{tabular}

\section{DISCUSSION}

When planning general anaesthesia one should monitor ammonia levels perioperatively in order to prevent delayed awakening by preventing neurological sequelae of the disease.

Stress response from surgical stimuli leads to enhanced protein breakdown leading to increase generation of ammonia. In patients with citrullinemia, defective urea cycle will result in accumulation of toxic byproducts of ammonia amidst catabolic states.
The goal of anaesthesia should be to optimize the patient's ammonia levels preoperatively with treatments, such as phenylacetate and benzoate, and to select anaesthetics based on their ability to prevent elevations in catecholamine and cortisol concentrations, in turn, preventing hyperammonemia intraoperatively.[]

Our management of the patient before surgery involved glucose supplementation and sufficient hydration to prevent a catabolic state.

Patients with citrullinemia commonly dehydrated. Appropriate intravenous fluid resuscitation and maintenance may help in 
Annals of International Medical and Dental Research

E-ISSN: 2395-2822 | P-ISSN: 2395-2814

Vol-8, Issue-2 | March-April 2022

DOI: 10.53339/aimdr.2022.8.2.1

Page no- 01-04 | Section- Research Article (Anesthesiology)

preserving anabolic physiology. Adequate caloric supplementation with carbohydrates and protein restriction also improves the anabolic state while optimizing utilization of energy.

Intraoperatively, the action of clonidine on $a-2$ receptors may have played a role in preventing hyperammonemia by reducing the overall stress response in our patient. In our case, we were able to avoid general anaesthesia by using the opioid sparing and analgesic effects of clonidine and femoral sciatic nerve block, which may have played an important role in managing anaesthesia and while avoiding a delayed emergence seen with general anesthesia in such group of patients \& local anaesthetics containing adrenaline should be avoided as they enhance protein catabolism

\section{REFERENCES}

1. Kourtis AP, Read JS, Jamieson DJ. Pregnancy and infection. N Engl J Med. 2014;370(23):2211-2218. doi:10.1056/NEJMra1213566

2. Ruitenbeek W, Kobayashi K, Iijima M, Smeitink JA, Engelke UF, De Abreu RA, et al. Moderate citrullinaemia without hyperammonaemia in a child with mutated and deficient argininosuccinate synthetase. Ann Clin Biochem. 2003;40(Pt 1):102-7. doi: 10.1258/000456303321016259.

3. Kasahara M, Ohwada S, Takeichi T, Kaneko H, Tomomasa T, Morikawa A, et al. Living-related liver transplantation for type II citrullinemia using a graft from heterozygote donor. Transplantation. 2001;71(1):157-9. doi: 10.1097/00007890-20010115000027.

4. Bachmann C. Long-term outcome of patients with urea cycle disorders and the question of neonatal
In our case, we focus on using adjuvants, such as clonidine, and nerve block to reduce the stress response to surgery and decrease the narcotic and paralytic requirements in patients with citrullinemia. The overall reduction in metabolic burden to the liver may play a role in management of ammonia levels, whereas the decrease in drug requirements may improve speed of recovery in a patient with citrullinemia after anaesthesia.

\section{CONCLUSIONS}

This report describes an uneventful management of patient with citrullinemia type 1 posted for tension band wiring for fractured patella.

screening. Eur J Pediatr. 2003;162 Suppl 1:S29-33. doi: 10.1007/s00431-003-1347-z.

5. Salleh MR. Life event, stress and illness. Malays J Med Sci. 2008;15(4):9-18.

6. Whitington PF, Alonso EM, Boyle JT, Molleston JP, Rosenthal P, Emond JC, Millis JM. Liver transplantation for the treatment of urea cycle disorders. J Inherit Metab Dis. 1998;21 Suppl 1:112-8. doi: 10.1023/a:1005317909946.

7. Gharavifard M, Sabzevari A, Eslami R. Anesthetic management in a child with citrullinemia: a case report. Anesth Pain Med. 2014;4(3):e21791. doi:10.5812/aapm.21791

Source of Support: Nil, Conflict of Interest: None declared 